\title{
A QUEM PERTENCEM NOSSAS ESCOLAS?
}

\author{
Rogério Cunha de Castro* \\ lattes.cnpq.br/5701132841967055 \\ Lia Ciomar Macedo de Faria** \\ lattes.cnpq.br/2897590944180460
}

\begin{abstract}
Resumo: O fechamento arbitrário de escolas pela Rede Estadual de Educação de São Paulo, exatamente no momento em que celebramos o sesquicentenário do Congresso de Genebra (1866), momento em que os internacionalistas congregados em torno da Associação Internacional dos Trabalhadores elegeram a educação como uma das suas principais bandeiras, reconduz as questões educacionais ao centro das discussões, consagrando-as como uma das nossas mais pungentes demandas. Nesse sentido, observamos que, no campo da história da educação, revisar experiências pedagógicas do passado nos auxilia a encontrar pistas e indícios de permanências que podem ancorar nossas lutas pela educação pública deste século XXI.
\end{abstract}

Palavras-chave: Associação Internacional dos Trabalhadores; Escolas Modernas; Escolas Ocupadas; São Paulo.

\section{TO WHOM DO OUR SCHOOLS BELONG?}

\begin{abstract}
The arbitrary closure of public schools in São Paulo, at exactly the time when we celebrate the 160th Geneva Congress (1866), a time when the internationalists gathered around the Workers' International Association elected education as one of its main flags, reappoints educational issues to the center of discussions, consecrating them as one of our urgent demands. In this sense, the field of History of Education, is important to review educational experiences of our past because they helps us to find evidences and clues of continuities that can anchoring our struggles for public education in this XXI century.
\end{abstract}

Keywords: International Workers Association; Modern Schools; Ocupated Schools; São Paulo.

\footnotetext{
* Doutor em Educação. Docente do Colégio Pedro II (Brasil). Contato: rogeriodecastro1973@gmail.com.

** Doutora em Educação. Docente da Universidade do Estado do Rio de Janeiro (Brasil). Contato: liafolia11@gmail.com.
} 
De certo tempo a esta parte se tem notado que o ensino racionalista se está desenvolvendo em S. Paulo, tanto na capital como no interior. Assim é que a despeito da crise, cujas consequencias se têm manifestado desastrosamente, há iniciativas que vingam e permanecem, produzindo frutos relativos á possibilidade do momento. Tais são, por exemplo, as que se referem á instrução da infância proletária. (...) Oxalá os protagonistas dessa grandiosa obra de regeneração social tenham imitadores! (O INÍCIO, 4/9/1915).

Nesse contexto político conturbado em que celebramos, também no Brasil, o sesquicentenário do Congresso de Genebra (1866), a questão educacional enquanto objeto do processo revolucionário, aspecto ressaltado pelos delegados da Associação Internacional dos Trabalhadores ${ }^{1}$, ainda permanece como uma das principais demandas. Assim, 150 anos após o primeiro congresso da AIT, a perspectiva do fechamento arbitrário de escolas integradas à Rede Estadual de Educação de São Paulo deflagrou uma sequência de ocupações que se expandiu por outros estados da federação.

Ao surpreender os governos e as próprias vanguardas sindical e estudantil, reunidas em entidades de classe que, não raro, transformaramse em correias de transmissão de partidos políticos, tais grupos parecem reivindicar outro paradigma: as escolas dos movimentos sociais. Dessa maneira, tal esforço de "desescolarização", que compreenderemos aqui enquanto iniciativa de desburocratização do ensino, tanto aponta para a perspectiva de que a autogestão constitui um caminho mais adequado para o convívio escolar, quanto insere seus membros numa determinada tradição de lutas.

A organização de comissões de limpeza, pedagogia, comunicação e manutenção, assim como o apoio mútuo e as relações federadas entre as

\footnotetext{
${ }^{1}$ A partir de uma visita de operários franceses a Londres para discutir questões referentes à exposição internacional, espécie de feira na qual os países apresentavam aspectos de sua cultura, indústria e comércio, iniciou-se o desenho de uma associação operária que ultrapassasse fronteiras nacionais. Em 1864, naquela mesma capital, constituiu-se a Associação Internacional dos Trabalhadores, organização que manteria congressos regulares até 1871, quando a guerra franco-prussiana terminou por comprometer a regularidade dos debates.
} 
ocupações aproximam os estudantes da democracia direta reivindicada pelos internacionalistas, reinserindo o debate sobre a educação no seio da classe trabalhadora. Por outro lado, pressionados pela justiça a desocupar seus próprios espaços, dados os subsequentes mandados de reintegração de posse, esses jovens recuperaram intuitivamente algumas questões que orientaram as deliberações do Congresso de Lausanne (1867).

Cientes de que o futuro dos trabalhadores deveria orientar à formação dos futuros trabalhadores, os internacionalistas, reunidos no Congresso de Lausanne, deliberaram sobre uma educação que servisse à emancipação da classe. Nesse sentido, partindo do princípio ético de extinguir as diferenças sociais, divisaram a substituição do individualismo burguês pela valorização das diferentes individualidades, demonstrando que, definitivamente, nenhum modelo educacional prescinde à ideologia que o concebeu.

Em "O apoio mútuo", Piotr Kropotkin² elucida como a ideologia orienta nossas maneiras de ser, pensar e agir. Ao redarguir o pensamento liberal, esse célebre geógrafo recorreu aos exemplos da natureza para rejeitar a competição enquanto lei social, identificando os grupos capazes de desenvolver a colaboração entre pares como mais aptos à sobrevivência. Nesse sentido, em sua análise sobre o comportamento das águias, constatou que as aves mais velhas e experientes chamam a atenção das mais jovens para o exercício da caça, permitindo que estas possam aprender através da observação. Não obstante o ensinamento prestado, saciam sua necessidade mais primária e assumem uma posição na qual consigam vigiar o ambiente, permitindo que os aprendizes usufruam da presa em segurança.

Enquanto estudava a fauna das estepes russas, viu certa vez uma águia de espécie gregária (cauda branca, Halioetos abicilla) que se elevava aos céus; durante meia hora, a águia observou amplas paragens, em silêncio, quando repentinamente ressonou

\footnotetext{
2 Reconhecido geógrafo russo que abdicou sua origem aristocrática e uma promissora carreira militar para dedicar-se ao estudo das ciências e à militância político-social. Tal opção, somada aos sucessivos exílios, impediram-no de assumir cargos de prestígio em academias como a Sociedade Geográfica Russa. Entre suas obras, destacam-se “A Conquista do Pão" e "Mutualismo: uma questão de evolução".
} 
seu penetrante granido. Em pouco tempo, outra águia respondeu seu apelo, aproximando-se dela em voo, as quais se uniu uma terceira, uma quarta, entre outras, até que se juntaram nove ou dez, para que em conjunto se perdessem de vista. Depois de meio dia, Syvertsof alcançou o lugar para o qual haviam se dirigido, ocultando-se numa ondulação da estepe de onde pode observar o bando em torno do cadáver de um cavalo. As águias mais velhas, que geralmente se alimentam primeiro, conforme o costume de urbanidade entre elas, já estavam pousadas no cimo dos montes de feno, na condição de sentinelas, enquanto as jovens se alimentavam (...). (KROPOTKIN, s.d., p. 54-55).

Como se vê, Kropotkin reorientou o significado dos fenômenos naturais numa proposta diametralmente distante daquela preconizada pelo chamado darwinismo social3. De acordo com sua teoria, o apoio mútuo assume a condição de lei primitiva, da qual nos distanciamos na mesma proporção em que a civilização nos afasta da natureza. Em outras palavras, num sentido contrário à desumanização que sofremos quando passamos a competir, Kropotkin reconhece, no exemplo das águias, o caminho adequado para recuperarmos a humanidade: o mutualismo.

O que pretendemos demonstrar é que os estudantes brasileiros, ao ocuparem suas instituições de ensino, imprimiram nesses espaços uma dinâmica distinta daquela que, até então, preponderava no cotidiano escolar. Tal proposta alternativa, por sua vez, permite entrever que as relações de ensino/aprendizagem, assim como as demais atividades sociais, não são concebidas fora de uma determinada ideologia. Logo, suas contestações ao modelo tradicional apontam para a percepção de que este, ao confundir enriquecimento intelectual com o êxito nos exames, contribui para instrumentalizar o saber e reforçar as diferenças sociais.

Com base nessas considerações, arriscamos dizer que os estudantes reconhecem que suas escolas não conseguem prepará-los para a competitividade expressa nos exames de ingresso nas universidades, circunstância que talvez os permita alcançar a consciência de sua exclusão, reforçando o desprendimento em relação às aulas formais que deixam de re-

\footnotetext{
3 Termo empregado para designar um conjunto de teorias sobre as sociedades humanas, ancoradas nos escritos e conclusões de Charles Darwin, mais especificamente em sua obra "A origem das espécies".
} 
ceber. Ao mesmo tempo, ao assumir o protagonismo na gestão da escola, tornam-se os principais mestres de si, organizando-se a partir de suas bases numa direção que, tal como afirmamos anteriormente, fora preconizada pelos delegados da Primeira Internacional.

Entre as deliberações do Congresso de Lausanne, encontramos a organização de escolas-oficinas que superem o trabalho alienado e a separação artificial entre saber e fazer, considerados àquela altura como pilares do Capitalismo. Com base nessa linha argumentativa, segundo a qual o pensamento e a ação estabelecem uma "dialética serial"4 que orienta a emancipação da classe trabalhadora, reconhecemos as experiências forjadas a partir dos congressos da Internacional como lastro capaz de oferecer elementos significativos para a compreensão das tensões sociais que alcançam nossas escolas.

Para Pierre-Joseph Proudhon5, filósofo cujo pensamento inspirou os delegados da AIT, o trabalho deveria constituir um verdadeiro instrumento pedagógico, através do qual os estudantes poderiam, desde tenra idade, capacitar-se para sua futura condição nas fábricas ${ }^{6}$. Ainda de

4 Divergindo da concepção dialética de Hegel, a "dialética serial" proposta por PierreJoseph Proudhon não estabelece, necessariamente, uma relação permanentemente antagônica entre teses. Apesar de contraditórias, elas podem equilibrar-se numa tensão contínua, sem que sejam superadas por uma "síntese".

5 Tipógrafo e deputado, Pierre-Joseph Proudhon ficou conhecido pela autoria das teses mutualistas que muito influenciaram os primeiros congressos da Associação Internacional dos Trabalhadores. Considerado como artífice da "filosofia do trabalho", encontrou no federalismo autogestionário um recurso para a superação das diferenças sociais.

6 "A educação foi para Proudhon uma constante preocupação, e a educação do povo pelo povo, a demopédia, uma exigência permanente. Sua concepção da educação é simultaneamente ampla e estreitamente articulada com o trabalho. Ele preconiza, com efeito, a igualdade entre a formação intelectual e a formação profissional que ele denomina "politecnia da aprendizagem". Ela é, além do mais, um instrumento de realização do indivíduo e uma alavanca de emancipação social. Para ele, "a organização do ensino é simultaneamente a condição da igualdade e a sanção do progresso". Mas, para isso, ela deve emancipar-se por sua vez, do julgo estatista ou religioso que não visa, pela instrução elementar, senão a encerrar a juventude e o futuro produtor "na certeza de suas funções parcelares pois, sem garantia e sem controle das associações operárias, a criança enviada às escolas será sempre um jovem servo adestrado para a servidão, no melhor dos interesses e da segurança das classes superiores". Ora, acrescenta Proudhon, "queremos trabalhadores civilizados e livres". (LENOIR, 2007, p. 19). 
acordo com o intelectual francês, a politecnia da aprendizagem proporcionaria a inflexão entre pensar e fazer, estabelecendo um diálogo permanente entre esses dois aspectos primordiais para a formação de homens e mulheres conscientes. Na percepção do autor de "A propriedade é um roubo" (1998), a instrumentalização do saber e sua apropriação pelo mercado tanto transformam as escolas em pilares do capitalismo, quanto convertem seus trabalhadores em agentes do capital, condições que obliteram o êxito pelo trabalho e submetem a ascensão social ao exercício da cumplicidade com o sistema.

Nesse sentido, a concepção educacional de Proudhon preconiza um conjunto de alternativas capazes de restituir as escolas ao poder popular. Entretanto, a perspectiva de poder delineada por Proudhon não pressupõe uma assimetria entre os membros de uma mesma comunidade. Ao contrário, prioriza a horizontalidade das decisões, circunstância que carece de ser vivenciada, simultaneamente, nas escolas e em todas as esferas deliberativas das associações profissionais, de bairro, fábrica e demais instâncias constitutivas das comunas de produtores/consumidores.

Outra proposta que exerceu grande influência sobre os trabalhadores envolvidos com os congressos da AIT foi o conceito de Instrução Integral. Defendido por Mikhail Bakunin, que participou do Congresso da Basileia (1869), tal conceito reconhece a liberdade como uma construção coletiva, para a qual a superação do trabalho alienado deve contar com uma instrução que contemple os aspectos físico, intelectual e social. Nessa ótica, segundo a qual a ética precisa ser praticada para ser compreendida, os futuros trabalhadores necessitam de um ambiente escolar no qual possam desenvolver com plenitude suas aptidões, preparando-se para uma vida autodeterminada através da ação direta em todas as esferas da sociedade. De acordo com o revolucionário russo:

O sustento, a educação e a instrução tanto científica quanto industrial, inclusive todos os ramos do ensino superior, igual para todas as crianças de ambos os sexos, e obrigatória até a maioridade, às custas da sociedade. (...) As crianças não são propriedade de ninguém, nem de seus pais, nem mesmo da sociedade - 
elas pertencem à sua liberdade futura. (BAKUNIN, 2009, p. 82).

Portanto, os operários reunidos nos congressos da Associação Internacional dos Trabalhadores, numa direção contrária aos congressos acadêmicos de hoje, cada vez mais inseridos numa lógica de mercado7, identificaram no apoio mútuo o caminho para a construção coletiva da liberdade, reconhecendo que a essência das antinomias do capitalismo está na sobreposição do Capital ao Trabalho. Ainda de acordo com essa parcela dos internacionalistas, que após o rompimento com os partidários de Carl Marx se reorganizaram no Congresso Antiautoritário de Saint-Imier $(1872)^{8}$, o sistema capitalista, amparado pelo que compreenderam como "tirania do sufrágio", fundamenta-se na seleção dos "escolhidos", reproduzindo a desigualdade econômica através da ilusão da igualdade jurídico/política.

Ao mesmo tempo, ao reivindicarem uma instrução que politizasse o espaço da escola, os internacionalistas rejeitaram o conceito de cidadania burguesa, circunstância que requereu, por conseguinte, a formação do "anticidadão". Esse não cidadão, cônscio da origem de sua infelicidade e preparado para a revolta, deveria encontrar na escola o ambiente adequado para construir suas próprias condições de luta, reconhecendo na

\footnotetext{
7 "Em nome da "segurança nacional", o intelectual acadêmico se despe de qualquer responsabilidade social quanto ao seu papel profissional, a política das "panelas" acadêmicas de corredor universitário e a publicação a qualquer preço de um texto qualquer se constituem no metro para medir o sucesso universitário. Nesse universo não cabe uma simples pergunta: o conhecimento a quem e para que serve? Enquanto esse encontro entre educadores, sob o signo de Paulo Freire, enfatiza a responsabilidade social do educador, da educação não confundida com inculcação, a maioria dos congressos acadêmicos universitários serve de "mercado humano", onde entram em contato pessoas e cargos acadêmicos a serem preenchidos, parecidos aos encontros entre gerentes de hotel, em que se trocam informações sobre inovações técnicas, reveem-se velhos amigos e se estabelecem contatos comerciais". (TRAGTEMBERG, 2004, p. 1617).

8 Após o rompimento entre os partidários de Carl Marx e Mikhail Bakunin que divergiam, entre outros aspectos, no que se refere à autonomia das seções aderentes à Internacional, os relojoeiros do Vallon suíço organizaram a chamada Internacional Antiautoritária, na qual endossaram a autonomia e a solidariedade entre as federações como uma das estratégias para a emancipação dos trabalhadores.
} 
ação direta e no mutualismo os meios para o desenvolvimento de uma sociedade livre.

Assim, aprovada durante o Congresso de Bruxelas (1868), a moção sobre a educação prescrevia que as seções da AIT fundassem escolas dedicadas à Instrução Integral e à inserção dos estudantes na luta de classes, sem deixar de considerar seus meios e suas necessidades enquanto futuros trabalhadores. Poucos anos depois, com a deflagração da Comuna de Paris 9 (1871), as primeiras iniciativas escolares norteadas por tais princípios foram levadas a termo, malgrado às circunstâncias conturbadas que caracterizaram os 72 dias em que os comunalistas reorganizaram a sociedade parisiense. Dessas iniciativas, tomou parte o professor Paul Robin, a quem os internacionalistas haviam encarregado de redigir a moção aprovada em Bruxelas. Sobre as escolas da Comuna, Lissagaray ${ }^{10}$ argumenta que:

Nada se saberia dessa revolução em matéria de educação sem as circulares das municipalidades. Várias haviam reaberto as escolas abandonadas pelas congregações e pelos professores primários da cidade, ou tinham expulsado os padres que lá restavam. A do XX Distrito vestiu e alimentou as crianças, lançando assim as primeiras bases das Caixas Escolares, tão prósperas a partir de então. A delegação do IV Distrito dizia: "Ensinar a criança a amar e a respeitar seu semelhante, inspirar-lhe o amor à justiça, ensinar-lhe que deve se instruir tendo em vista o interesse de todos: eis o princípio moral em que doravante repousará a educação comunal". "Os professores das escolas primárias e das creches", prescrevia a Delegação do XII Distrito, "empregarão exclusivamente o método experimental e científico, que parte sempre da exposição dos fatos físicos, morais e intelectuais". Ainda estava longe de ser um programa completo. (LISSAGARAY apud MELO, 2001, p. 127-128).

\footnotetext{
9 Entre os meses de março e maio de 1871, federações de bairro organizaram uma democracia direta que resistiu às investidas do governo transferido para Versalhes. Ainda no contexto das guerras franco-prussianas, as tropas aprisionadas pelo Império Alemão foram libertas para engrossar as fileiras da guerra civil, colocando termo à Comuna e suas realizações autogestionárias no campo da administração, produção e cultura.

${ }^{10}$ Hippolyte Prosper-oliver Lissagaray participou da Comuna e se notabilizou por sua obra "História da Comuna de 1871", na qual descreve os acontecimentos que tiveram lugar em Paris.
} 
Contudo, findo o exílio imposto aos comunalistas, Robin conseguiu desenvolver a primeira experiência duradoura no campo da instrução proletária, pondo em prática a Instrução Integral defendida pela Primeira Internacional. Ao assumir a direção do orfanato público em Cempuís, o educador francês manteve os princípios determinados pelo Programa Educacional do Comitê para o Ensino Anarquista (1882). De acordo com esse programa, a educação deveria ser:

a) integral, isto é, favorecer ao desenvolvimento harmonioso de todo o indivíduo e fornecer um conjunto completo, coerente, sintético e paralelamente progressivo em todos os domínios do conhecimento intelectual, físico, manual e profissional, sendo as crianças exercitadas nesse sentido desde os primeiros anos;

b) racional, isto é, fundamentado na razão e conforme os princípios da ciência atual, e não na fé; no desenvolvimento da dignidade e da independência pessoal, e não na piedade e na obediência; na abolição da ficção divina, causa eterna e absoluta da servidão;

c) misto, isto é, favorecer a coeducação sexual numa comunhão constante, fraternal entre meninos e meninas. Essa coeducação, ao invés de constituir um perigo, afasta do pensamento da criança as curiosidades malsãs, e torna-se uma ocasião para sábias condições que preservam e asseguram uma alta moralidade;

d) libertário, isto é, numa palavra, consagrar em proveito da libertação o sacrifício progressivo da autoridade, uma vez que o objetivo final da educação é formar homens livres que respeitem e amem a liberdade alheia. (KROPOTKIN apud LUIZETTO, 1986, p. 24).

Desse modo, entre os anos de 1880 e 1894, período em que esteve à frente do Orfanato Prévost, Robin suprimiu os exames e as diferenças de gênero, estimulou o estudo das línguas e das artes, introduziu a prática de esportes e o aprendizado em oficinas de encadernação, agricultura, costura, marcenaria, manutenção e limpeza nas quais os estudantes deveriam vivenciar o apoio mútuo. Tal aspiração em formar homens e mulheres integrais, valorizou o convívio entre meninos e meninas e o cuidado com seus desenvolvimentos físico, intelectual e social enquanto estratégia para a construção coletiva da igualdade. Vejamos:

Não sabemos de forma precisa como será a organização social no futuro. Qualquer que venha a ser, caso desejemos que pros- 
pere precisamos, inevitavelmente, que se cumpra a harmonia entre os desejos em lugar do irracionalismo dos instintos, aspecto que demanda uma educação que nos aproxime mais, sem dividir-nos. (ROBIN, 1981, p. 42).

O empenho de Robin na organização de uma comunidade que aproximasse seus membros, sem assimetrias de classe ou gênero, serviu como argumento para os inquéritos administrativos que motivaram sua exoneração em 1894. Ainda que omitissem a preocupação com as questões de classe, os meios conservadores não esconderam a apreensão com a ideia de harmonizar meninos e meninas num mesmo espaço escolar. Entretanto, apesar de ceifado ainda em botão, o legado de Cempuís foi de grande importância para o estabelecimento da Escola Moderna (1901), instituição que se tornaria um ícone para os defensores da Instrução Integral.

Inspirado pelas utopias educacionais da Primeira Internacional, Francisco Ferrer y Guardia fundou sua Escola Moderna em Barcelona, iniciativa que logo contou com similares que ultrapassaram as fronteiras espanholas. Para Ferrer, a luta contra a aristocracia deveria incluir a superação de qualquer elite do pensamento, razão pela qual sublinhou a importância das suas "missas de domingo". Nesse dia consagrado ao repouso, no qual as famílias espanholas compareciam ao culto católico, Ferrer abriu as portas de sua escola e estimulou a prática da ação direta entre os membros daquela comunidade. A esse respeito, Bakunin (2009, p. 57) considera que:

A escola deve substituir a Igreja com a imensa diferença que esta, ao distribuir sua educação religiosa, não tem outro objetivo senão eternizar o regime da menoridade humana e da autoridade pretensamente divina, enquanto a educação e a instrução da escola, não tendo, ao contrário, outro fim senão a emancipação real das crianças quando chegarem à maioridade, não serão outra coisa senão sua iniciação gradual e progressiva à liberdade pelo triplo desenvolvimento de suas forças físicas, de seu espírito e de sua vontade. 
O que se observa é que o desejo de substituir a verticalidade das decisões pela autogestão do poder ${ }^{11}$, aponta para a percepção de que a transformação do cotidiano escolar se insere num conjunto mais amplo de mudanças: a revolução social. Nessa perspectiva, Ferrer considerou que se por um lado a educação não promove sozinha a revolução, tampouco esta se completa sem ela, dado o risco de perpetuar uma elite intelectual capaz de manter as diferenças entre os que pensam e os que fazem.

Além disso, a pesquisa assinala que o esforço de congregar a comunidade aos domingos foi conjugado à iniciativa de realizar visitas estudantis às fábricas de Barcelona. Muito provavelmente, o educador catalão pretendia estimular, assim como em suas reuniões domingueiras, o debate acerca das condições de vida da maioria do povo espanhol. Entre os relatos dessas atividades, destacamos:

Um incidente ocorreu naquela ocasião. Várias crianças, incomodados pelo calor e pelo odor desagradável dos materiais e ingredientes, não quiseram entrar no último departamento visitado, proporcionando uma consideração final. As operárias e operários que trabalham nessas fábricas iniciaram suas atividades ainda jovens, muitos sem ainda ter consolidado e fortalecido seus organismos, sem ter completado sua educação e instrução. Também se incomodavam com o calor e o odor daqueles materiais, mas sobre esses incômodos impôs-se a necessidade, que fará com que permaneçam ali até a morte, desfecho que sempre ocorre antes da época geralmente fixada pelas condições normais do organismo humano. Admiravelmente, a ciência e a industria tem realizado maravilhas, como as que se efetuam atra-

11 "Dominação e autogestão estão diretamente relacionadas ao conceito de poder que será aqui definido de acordo com a segunda abordagem Ibáñez, como assimetria nas relações de força. Definir o poder dessa maneira permite conceitua-lo, mais especificamente, como uma relação que se estabelece nas lutas e disputas entre diversas forças sociais, quando uma(s) força se impõe à(s) outras; poder e relação de poder funcionam, dessa maneira, como sinônimos. (Corrêa, 2011a) O vínculo entre a dominação, a autogestão e o poder se dão por meio da noção de participação; considerando que a participação é estabelecida pelas relações de poder, ela pode ser maior, aproximando-se da noção de autogestão, ou menor, aproximando-se da dominação. Dominação e autogestão seriam, assim, tipos-ideias, das relações de poder, tomando por base um eixo da participação; quanto mais dominador for o poder, menor participação; quanto mais autogestionário, maior participação". (CORRÊA; SILVA; SILVA, 2015, p. 112-113). 
vés dessas máquinas. Contudo, a elas se opõe, desgraçadamente, um terrível detalhe: seus benefícios não são distribuídos eqüitativamente. Conforme se verificou, aqueles operários condenados a suportar continuamente essas condições, insuportáveis para alguns visitantes, passam muitas penalidades e acabam, em geral, morrendo prematuramente. Além disso, recebem exíguos salários, fazendo com que os donos legais das máquinas, produtos e utilitários, quando fracassam seus negócios, enriqueçam e gozem com os seus das conseqüentes vantagens. Assim, deduzimos que para a justiça social elevar-se ao adiantado nível da ciência industrial, temos que trabalhar com todo empenho para levarmos dignidade e felicidade a toda a espécie humana. Tais foram essas considerações, sumariamente expostas, que nossos alunos muito se impressionaram nessa proveitosa excursão, que constitui um dos vários complementos instrutivos empregados em nossa escola. (FERRER Y GUARDIA, 1976, p. 133-134).

As circunstâncias vivenciadas na fábrica pelos meninos e meninas da Escola Moderna, ao menos aquelas que seu diretor permite que alcancemos, apontam para o fato de que o educandário de Ferrer, embora possa ser inserido no conjunto de iniciativas que receberam o epíteto de Escola Nova, apresenta um aspecto em específico: a inserção deliberada da luta de classes no currículo escolar. Desta forma, o desejo de ultrapassar formas indiretas de gestão parece ter proporcionado contornos particulares aos recursos pedagógicos cada vez mais empregados a partir do século XX.

Outra tentativa de suscitar um aprendizado que equacionasse os desejos individuais e as necessidades coletivas, estabelecendo estratégias de sociabilidade que atentam, entre outros aspectos, para o pertencimento da escola e o protagonismo discente, consistiu na sociedade estudantil "A Solidária". Tal organismo da Escola Oficina de Lisboa ${ }^{12}$, que contou com a colaboração do celebrado professor Adolfo Lima ${ }^{13}$, realizou saraus,

12 Situada no bairro lisboeta da Graça, foi fundada por maçons agrupados na Sociedade Promotora de Creches em 1902. Já em 1905 a Escola Oficina $\mathrm{n}^{\circ} \cdot 1$ oferecia o curso profissionalizante de marcenaria. Entre os anos de 1907 e 1918, a concepção libertária preponderou na instituição, perdendo gradativamente sua influência após a saída de Adolfo Lima do seu quadro de professores.

${ }^{13}$ Adolfo Lima foi um conhecido educador português, formado em direito pela Universidade de Coimbra e docente da Escola Normal Primária de Lisboa. Colaborou e 
aulas passeio e uma cantina autogestionária. Num dos seus artigos publicados em A Lanterna, Neno Vasco ${ }^{14}$ trata com entusiasmo do protagonismo dos estudantes à frente dessa organização:

E o meio prático que, alêm de outros, a Escola-Oficina ideou para ensinar a moral? Pôs a moral em acção na Solidária, associação dos alunos cujo <objectivo é estabelecer relações de solidariedade entre os sócios e respectivas famílias $>$. Os pequenos aprendem a prestar uns aos outros apoio moral e material, a associar-se. Assim, por exemplo, em caso de doença ou acidente, os infantis sócios dividirão entre si a tarefa do inválido. A Solidária realiza festas e saraus, promove excursões e visitas, organiza passeios e piqueniques, mantêm o lanche escolar, uma espécie de <cozinha comunista $>$ que fornece aos alunos uma merenda em cada dia de aulas. (A LANTERNA, 24/01/1914).

De acordo com António Candeias (1992), "A Solidária” chegou a assumir boa parte do funcionamento da Escola Oficina, fazendo com que a ação direta e o apoio mútuo preponderassem naquele cotidiano escolar15. Portanto, esse esforço para educar de outra forma assinala um ponto fora da curva de inflexão entre a Escola Moderna e o conjunto de práticas pedagógicas que, a partir das proposições de Adholpe Ferriere ${ }^{16}$, receberam a alcunha de Escola Nova. Paralelamente, o desejo de politizar a

dirigiu diversos periódicos ligados aos temas educacionais, além de elaborar uma obra diversificada sobre o tema na qual constam diversas peças teatrais.

14 Gregório Nazianzeno Moreira de Queirós e Vasconcelos foi um advogado português que ingressou nas fileiras anarquistas durante sua morada no Brasil. Atuou em diversas frentes de militância, tanto no Brasil quanto em Portugal. Para maiores informações sobre Neno Vasco, consultar: SAMIS, 2009.

15 "Será durante esta fase que serão suprimidas as faltas, que os horários se flexibilizarão, que terminarão de vez os exames, que os castigos físicos serão terminantemente proibidos, que será criada uma associação de estudantes denominada "A Solidária" que se encarregará da gestão de uma parte da escola, que será lançado o regime de coeducação, e que todo o modelo pedagógico, incluindo as formas específicas dos modelos de aprendizagem a ela associados serão afixados e postos em prática. Será a altura em que podemos afirmar que sem ambigüidades, esta escola trabalha sob um registro muito claro de que antes classificaríamos como modelo educacional libertário". (CANDEIAS, 1992, p. 162).

16 Pedagogo suíço considerado um dos pioneiros do movimento denominado Escola Nova, movimento que preconizou novas estratégias que consideravam os interesses dos estudantes, suas diferentes individualidades, além da autonomia docente para um ensino pautado pela realidade social de cada comunidade escolar. 
escola, aspecto preconizado pelos postulantes da pedagogia ferretiana, parece assumir uma direção oposta ao processo de psicologização da educação, concepção que ganhou muitos adeptos entre os escolanovistas.

Em contraste com esse conjunto de experiências, o projeto de lei identificado pelo vulgo "Escola sem Partido", assume concepções que antagonizam com as propostas colocadas em prática pela Escola Moderna. Afinal, trata-se de uma perspectiva conservadora e auto referenciada, que não prioriza a comunidade escolar como instância capaz de resolver possíveis divergências, substituindo-a pelo denuncismo que judicia as relações e criminaliza o conjunto dos trabalhadores da educação. Tal proposta coíbe o convívio em meio às diferenças, circunstância apontada pela Escola Moderna como condição para que os estudantes encontrem, na prática do consenso e da tolerância, uma maneira de preservar o bem comum sem comprometer suas individualidades.

Assim, ao reivindicar uma neutralidade ideológica que rejeita a inserção das antinomias sociais no espaço da escola, depreciando a função desta enquanto mediadora, o projeto "Escola sem Partido" propõe, ao fim e ao cabo, a sobreposição do privado sobre o público, ensejando a uniformidade do pensamento num ambiente incumbido de assegurar a diversidade.

Ao analisarmos o conceito de "neutralidade sindical" defendido pelo Primeiro Congresso Operário Brasileiro (1906), observamos a mesma preocupação com a pluralidade de concepções presente na Escola Moderna. Portanto, ressaltamos que a ideia de "neutralidade" defendida pelos trabalhadores não significava "omissão" ou "ausência" de valores. Ao contrário, aponta para o fato de que as escolas, assim como os sindicatos operários, devem abranger diferentes correntes de pensamento, permitindo que seus membros acessem todos os princípios políticos e ideológicos.

Em outras palavras, para os educadores envolvidos com a Escola Moderna, o termo "neutralidade" não deveria significar a ausência de orientação ideológica, mas a coexistência de diferentes concepções que precisam ser compreendidas pelos estudantes, evitando-se que as instituições de ensino se convertam em "correias de transmissão". 
Para recuperarmos o exemplo assente em "A Solidária", sublinhamos que em nenhuma das suas assembleias se fez ouvir "a voz dos adultos, apesar de em todas elas ter estado presente, entre outros, Adolfo Lima” (CANDEIAS, 1992, p. 365). Ao respeitar o pertencimento dessa entidade, os educadores da Escola Oficina se limitaram a colaborar com seus aderentes, manifestando-se o menos possível, com vistas a evitar qualquer interferência no protagonismo dos estudantes na construção coletiva do consenso.

Tal preocupação, reafirma o entendimento de que os trabalhadores da educação devem auxiliar os estudantes na construção do próprio conhecimento, permitindo que "aprendam a aprender". Ao atuar nessa direção, os professores da Escola Oficina viabilizariam, numa analogia às águias descritas por Kropotkin, os meios necessários para o descondicionamento dos jovens, convertendo sua escola numa barricada capaz de interpor a comunidade ao pensamento único.

Para concluir nossa abordagem, observamos que a consciência de que a educação deve dirigir-se à classe trabalhadora foi partilhada pelos idealizadores das Escolas Modernas de São Paulo. Assim, enquanto “A Solidária” estimulava a ação direta e o apoio mútuo entre os estudantes da Escola Oficina de Lisboa, a Escola Moderna paulista se valeu do jornalzinho $O$ Início como estratégia para valorizar a autodisciplina e substituir o rigor dos exames. Vejamos:

No sábado, dia 6 de março, nós nos reunimos todos às 7 horas da manhã na nossa Escola e cantamos os hinos "A Mulher" e o "Primeiro de Maio". Depois meia hora saímos, e descemos a rua Catumbi, tomamos a travessa do mesmo nome, fomos pela rua dos Prazeres, descemos a rua Cachoeira e seguimos uma rua cujo nome eu não sei. Eu vi pelo caminho uma pontesinha na travéssa da rua Catumbi. Lá o nosso professor nos explicou que troncos da taquara se chamam rizônia e que esses troncos caminham debaixo da terra. Ao chegarmos ao rio Tietê vimos barcas dentro e fora do rio. Um menino estava nadando vestido de calças no meio do rio. Vimos as barcas no meio do Tieté e também uns meninos caçarem peixes. Depois brincámos de Caracol e Seranda-Serandinha. O João Bento, o Bruno, o Ernesto, o Carlos Chiesa e o Abílio Bento recitaram. Na ida vimos um cavalo morto e o Miniere botou flores em cima dêle. O professor disse 
que o Miniere fez bem de botar flores em cima do cavalo morto. $\mathrm{Na}$ volta o professor nos mandou pegar uma varinha com flores e pegamos tambem taquaras de bambú. O Abilio Bento fez um estoque para mim. Na ida e na volta nos sentámos em cima dum ventilador de exgôto. Chegámos à nossa Escola quando faltavam 25 minutos para as dez horas. Depois o professor nos deu os cadernos e fomos embora para nossas casas. (MAZZONE, O Início, 04/09/1915).

Através da redação de Edmundo Mazzone, observamos que a aula passeio convidou os estudantes ao exercício físico da caminhada, ao exercício reflexivo sobre o contexto em que viviam e, finalmente, ao exercício da solidariedade. Tal recurso, que privilegiou a curiosidade dos estudantes como ponto de partida para a efetivação da tríade física, intelectual e social que orienta a pedagogia ferretiana, parece apontar para as conclusões de António Lima:

(...) o assunto a tratar, é feito pelo aluno, pelos factos diários da vida escolar, em volta de nós, na natureza. (...) Não usamos portanto o livro, a lição de cor, a lição marcada; estas conduzem quási sempre, parece-nos, a uma má vontade, uma não aceitação agradável da aula (...). (LIMA, Boletim da Escola Oficina n.1, abril de 1918).

Sobre a instrução física, reconhecemos que tanto a caminhada quanto as brincadeiras infantis atuavam no sentido de estimular fisicamente as crianças. Ao mesmo tempo, a instrução intelectual pode ser percebida nas orientações do professor em relação ao vegetal que, muito provavelmente, trata-se de algum espécime de rizoma. Além disso, o repouso próximo à rede de esgoto sugere uma escolha premeditada, capaz de oferecer condições de confrontar a paisagem natural verificada nas margens do rio com os efeitos dos processos de urbanização e industrialização. Acrescentamos as demonstrações de solidariedade dos meninos Miniere, que depositou flores sobre o corpo do animal, e Abílio Bento, que providenciou um ramo de flores para o autor do texto, representam experiências vinculadas à instrução social, de tal modo que "a criança sempre rodeada de bons sentimentos, bons os terá para todos; bem tratada, tratará bem todos os outros, será serviçal para com todos, sobretu- 
do para com os mais fracos, como os mais fortes o são para com ela" (ROBIN, A Sementeira, 01-09-1916).

Reconhecemos, na assertiva de Robin, as considerações de Piotr Kropotkin acerca do individualismo e da competitividade que, via de regra, preponderam em nossa sociedade. Conforme sublinhamos, os educadores ferretianos compreendem que o Capital e o Estado precisam ser substituídos pela cooperação entre trabalhadores/consumidores, capazes de resolver, coletivamente, as decisões sobre suas demandas. Assim, o expediente de encontrar na horizontalidade das decisões uma estratégia de superação dos dissensos, através da compatibilização entre os desejos individuais e as necessidades coletivas, deveria ser amadurecido no ambiente escolar. Nessa lógica, tal politização do espaço da escola contribuiria para a liberdade constitua uma construção coletiva.

Em resumo, a valorização do aprendizado pelo trabalho, o estímulo ao protagonismo dos estudantes e a solidariedade entre as comunidades formadas pelas Escolas Modernas, parecem indicar o desejo de estabelecer, da maneira mais imediata possível, relações pautadas no apoio mútuo, na ação direta e no federalismo que fundamentam a sociedade preconizada pelos internacionalistas libertários e suas propostas no campo da educação. Por outro lado, tais princípios parecem ressurgir, ainda que intuitivamente, no movimento de ocupações deflagrado em São Paulo, sobretudo no que se refere aos seus métodos de organização e na aspiração de submeter o Estado às demandas estudantis.

Ao fim e ao cabo, compreendemos que no campo da história da educação, revisitar as experiências pedagógicas do passado nos auxilia a encontrar pistas e indícios de algumas permanências nas quais podemos ancorar nossas lutas pela escola pública deste século XXI. 


\section{Referências}

ANTONY, M. Os microcosmos. Experiências utópicas libertárias sobretudo pedagógicas: "utopedagogias". São Paulo: Expressão e Arte Editora; Editora Imaginário, 2011.

BAKUNIN, M.; KROPOTKIN, P.; JOYEUX, M.; CHAUVET, P.; DELHOM, J. A Comuna de Paris: considerações libertárias. São Paulo: Editora Imaginário, 2011

. A instrução integral. São Paulo: Imaginário; Instituto de Estudos Libertários; Núcleo de Sociabilidade Libertária do Programa de Estudos Pós-Graduados em Ciências Sociais da PUC-SP, 2003.

. A ciência e a questão vital da revolução. São Paulo: Faísca Publicações Libertárias; Editora Imaginário, 2009.

CANDEIAS, A. Educar de outra forma: a Escola Oficina n.1 de Lisboa 1905-1930. Tese (Doutorado) - Universidade do Porto, Porto, 1992

. Educar de outra forma: a Escola Oficina n.1 de Lisboa 19051930. Lisboa: Instituto de Inovação Educacional, 1994.

CANDEIAS, A.; NOVOA, A.; FIGUEIRA, M. H. Sobre a Educação Nova: cartas de Adolfo Lima a Álvaro Viana de Lemos (1923-1941). Lisboa: Universidade de Lisboa, 1995

CODELO, F. A boa educação: experiências libertárias e teorias anarquistas na Europa, de Godwin a Neill. São Paulo: Editora Imaginário, 2007.

CORRÊA, F. Bandeira Negra: rediscutindo o Anarquismo. Curitiba: Editora Prismas, 2015.

CORREAA, F.; SILVA, R. V.; SILVA, A. S. (org.). Teoria e história do Anarquismo. Curitiba: Prismas, 2015.

FERRER Y GUARDIA, F. La Escuela Moderna. Madrid: Ediciones Jucar, 1976.

KROPOTKIN, P. El apoio mutuo: um factor de la evolución. Cali: Ediciones Madre Tierra, [s.d.].

LENOIR, H. Educar para emancipar. São Paulo: Imaginário; Manaus: Editora da Universidade Federal do Amazonas, 2007.

ROBIN. P. Manifesto a los partidos de la educacion integral (um antecedente de la Escuela Moderna). Barcelona: José J.de Olañeta Editor, 1981.

SAMIS, A. R. Minha pátria é o mundo inteiro. Neno Vasco, o anarquismo e o sindicalismo revolucionário em dois mundos. Lisboa: Letra Livre, 2009. 
TRAGTENBERG, M. Educação e burocracia. São Paulo: Editora UNESP, 2012

. Sobre educação, política e sindicalismo. São Paulo: Editora UNESP, 2004

. Teoria e ações libertárias. São Paulo: Editora da UNESP, 2011.

Recebido em 15 de fevereiro de 2017. Aprovado em 28 de junho de 2017. 